\title{
Experimental Study of Subcooled Flow Boiling Heat Transfer on a Smooth Surface in Short-Term Microgravity
}

\author{
Yonghai Zhang ${ }^{1} \cdot$ Bin Liu $^{1} \cdot$ Jianfu Zhao ${ }^{2,3} \cdot$ Yueping Deng ${ }^{4} \cdot$ Jinjia Wei ${ }^{1,4}$ \\ Received: 6 March 2018 / Accepted: 16 May 2018 / Published online: 1 June 2018 \\ (C) Springer Science+Business Media B.V., part of Springer Nature 2018, corrected publication October/2018
}

\begin{abstract}
The flow boiling heat transfer characteristics of subcooled air-dissolved FC-72 on a smooth surface (chip S) were studied in microgravity by utilizing the drop tower facility in Beijing. The heater, with dimensions of $40 \times 10 \times 0.5 \mathrm{~mm}^{3}$ (length $\times$ width $x$ thickness), was combined with two silicon chips with the dimensions of $20 \times 10 \times 0.5 \mathrm{~mm}^{3}$. High-speed visualization was used to supplement observation in the heat transfer and vapor-liquid two-phase flow characteristics. In the low and moderate heat fluxes region, the flow boiling of chip $S$ at inlet velocity $V=0.5 \mathrm{~m} / \mathrm{s}$ shows almost the same regulations as that in pool boiling. All the wall temperatures at different positions along the heater in microgravity are slightly lower than that in normal gravity, which indicates slight heat transfer enhancement. However, in the high heat flux region, the pool boiling of chip S shows much evident deterioration of heat transfer compared with that of flow boiling in microgravity. Moreover, the bubbles of flow boiling in microgravity become larger than that in normal gravity due to the lack of buoyancy Although the difference of the void fraction in $x-y$ plain becomes larger with increasing heat flux under different gravity levels, it shows nearly no effect on heat transfer performance except for critical heat flux (CHF). Once the void fraction in $y-z$ plain at the end of the heater equals 1, the vapor blanket will be formed quickly and transmit from downstream to upstream along the heater, and CHF occurs. Thus, the height of channel is an important parameter to determine CHF in microgravity at a fixed velocity. The flow boiling of chip $\mathrm{S}$ at inlet velocity $V=0.5 \mathrm{~m} / \mathrm{s}$ shows higher CHF than that of pool boiling because of the inertia force, and the CHF under microgravity is about $78-92 \%$ of that in normal gravity.
\end{abstract}

Keywords Microgravity $\cdot$ Flow boiling $\cdot$ Heat transfer $\cdot$ CHF

\section{Introduction}

Boiling heat transfer is considered as a highly efficient approach for heat transfer dissipation due to phase change.

This article belongs to the Topical Collection: Approaching the Chinese Space Station - Microgravity Research in China Guest Editors: Jian-Fu Zhao, Shuang-Feng Wang

Jinjia Wei

jjwei@mail.xjtu.edu.cn

1 School of Chemical Engineering and Technology, Xi' an Jiaotong University, Xi'an, 710049, China

2 CAS Key Laboratory of Microgravity, Institute of Mechanics, Chinese Academy of Sciences, Beijing, 100190, China

3 School of Engineering Science, University of Chinese Academy of Sciences, 19A Yuquan Rd, Beijing, 100049, China

4 State Key Laboratory of Multiphase Flow in Power Engineering, Xi'an Jiaotong University, Xi'an, 710049, China
In resent five decades numerous studies on pool boiling heat transfer have been conducted under different gravity levels (Di Marco 2003; Kim 2003; Ohta 2003; Zhao 2010; Colin et al. 2017). Compared with the results in normal gravity, the pool boiling heat transfer was enhanced in the low heat flux region, remained the same in the moderate heat flux region and deteriorated significantly in the high heat flux region (Zell et al. 1984; Oka et al. 1995; Kim et al. 2002; Herman Merte 2004; Raj et al. 2012; Dhir et al. 2012). In addition, the pool boiling heat transfer at low heat fluxes was found to be enhanced but the critical heat flux (CHF) was deteriorated in microgravity through the application of acoustic field (Sitter et al. 1998) and electric field (Di Marco et al. 2003). Very recently, the experimental investigation of pool boiling on a smooth silicon chip and micro-pin-finned chips in microgravity were conducted by Xue et al. (2011, 2013) and Zhang et al. (2014), they found that the heat transfer performance including heat transfer coefficient (HTC) and CHF can be improved significantly by the existence of micro-pin-fins. Therefore, the surface 
modification can be a very effective way to enhance pool boiling heat transfer in microgravity. However, flow boiling heat transfer is much more complicated in mechanisms than that of pool boiling. The documents of flow boiling heat transfer in microgravity $(\mu g)$ are very deficient even it can provide an effective process to prevent the formation of massive bubbles (Celata 2007).

The limited literature of flow boiling heat transfer at different gravity levels show that the main attention is paid to the boiling heat transfer performance and its flow pattern (Celata et al. 2007, 2009; Ohta 1997; Kawanami et al. 2007; Baltis et al. 2012; Narcy et al. 2014), flow boiling in micro/mini channels (Luciani et al. 2008; Brutin et al. 2013), bubble dynamics in convection boiling heat transfer (Serret et al. 2010; Ma and Chung 2001a), the boiling HTC in the low heat flux region (Ma and Chung 1998; Saito et al. 1994) and CHF (Ma and Chung 2001b). The results of Ma and Chung (1998, 2001a) and Saito et al. (1994) indicated the similar trend that the bubble departure diameter in $\mu g$ becomes larger than that in normal gravity, and this tendency deceases with the increase of inlet velocity, indicated that the influence of gravity level diminishes with increasing inlet velocity. These results provide valuable data to study the two-phase flow and bubble dynamics under different gravity levels. However, only a little literature about the CHF of flow boiling heat transfer under microgravity has been published. Ohta (1997) obtained limited flow boiling CHF data in microgravity at high inlet quality, but noted that he could not measure CHF accurately in the absence of local wall temperature measurements along the heated wall. Ma and Chung (2001b) investigated subcooled flow boiling of FC-72 across a heated $0.254 \mathrm{~mm}$ platinum wire by a $2.1 \mathrm{~s}$ drop tower. They found that the CHF was significantly lower in microgravity. However, the differences in both HTC and CHF between $\mu g$ and $1 g$ decreased with increasing flow rate. Zhang et al. (2005) tested a series of CHF at different inlet liquid velocities in a single-sided heating rectangle channel under normal and microgravity conditions and found that the heat transfer performance is very similar to the previous studies (Ohta 1997; Ma and Chung 2001b). Besides, the influence of gravity almost vanished and the flow boiling is inertiadominant as the inlet liquid velocity above $1.5 \mathrm{~m} / \mathrm{s}$. Konishi et al. (2015a, b) conducted the flow boiling experiments in a rectangular channel fitted with two opposite heating walls at liquid inlet velocities of $0.1-1.9 \mathrm{~m} / \mathrm{s}$, and the double-sided heating can get better heat transfer performance than that of single-sided heating at the same inlet velocity and heat flux.

From the previous literature review, it can be found that the research of CHF correlations and mechanistic models of flow boiling heat transfer in microgravity are extremely lack, despite extensive pool boiling and two-phase flow data and visualization results are available in the literature
(Konishi and Mudawar 2015). As is known, the CHF of flow boiling is affected by many factors, such as inlet velocity, geometry parameter of channel (Baldassari and Marengo 2013) and heater (Kureta and Akimoto 2002). Therefore, it is not reasonable to use a constant threshold velocity, such as $1.5 \mathrm{~m} / \mathrm{s}$ in Ref. Zhang et al. (2005), for the inertia-dominant flow boiling in different gravity conditions. The regulation of the threshold velocity for inertia-dominant flow boiling heat transfer under different conditions should be investigated systematically. In the present study, the flow boiling heat transfer characteristics of subcooled air-dissolved FC-72 on a smooth surface were studied in microgravity by utilizing the drop tower facility in Beijing. High-speed visualization was used to supplement observation in the heat transfer performance and vapor-liquid two-phase flow characteristics.

\section{Experimental Apparatus and Test Procedures}

\section{Experimental Apparatus}

The flow boiling heat transfer test facility system is presented schematically in Fig. 1. The test system comprises the pipeline system, testing section, data acquisition and visualization system. İn our previous study (Honda and Wei 2003), we have conducted the experiment to study the effects of degassed FC-72 and gas dissolved FC-72 on boiling heat transfer performance of micro-pin-finned surfaces. The results showed that at low heat fluxes just after incipience, the dissolved air significantly enhances heat transfer but the effect diminishes with increasing heat flux similar to that observed for the flat surfaces and the microporous, square finned surfaces by Rainey et al. (2003). Thus, the airdissolved FC-72 was used in the present study. With regard to the pipeline system, the working fluid (FC-72, $T_{\text {sat }}=$ $56{ }^{\circ} \mathrm{C}$ ) was pumped by a mini pump. The volume flow rate $\left(Q_{\mathrm{v}}\right)$, which was measured by a turbine flowmeter (ZHLW$60-600 \mathrm{~L} / \mathrm{h}$ ), was adjusted by a potentiometer. A tank with a capacity of $2 \mathrm{~L}$ and with a rubber bag was used to maintain the pressure of pipeline system at $1 \mathrm{~atm}$. In this study, the liquid subcooling $\left(\Delta T_{\text {sub }}\right)$ is approximately $15 \mathrm{~K}$ (which was sustained by an auxiliary heater, a condenser, and a PID temperature controller), and the liquid temperature $\left(T_{\mathrm{b}}\right)$ was measured by a platinum resistance thermometer (Pt-100A).

The test section with a size of $545 \times 80 \times 43 \mathrm{~mm}^{3}$ was made of polycarbonate to allow visualization. The flow boiling heat transfer occurred in a rectangular channel with the cross-sectional dimensions of $12 \times 3 \mathrm{~mm}^{2}$. The heater, with dimensions of $40 \times 10 \times 0.5 \mathrm{~mm}^{3}$ (length $\times$ width $\times$ thickness), was combined with two silicon chips, each with the dimensions of $20 \times 10 \times 0.5 \mathrm{~mm}^{3}$. For the heater, the test 
Fig. 1 Schematic diagram of the experimental apparatus

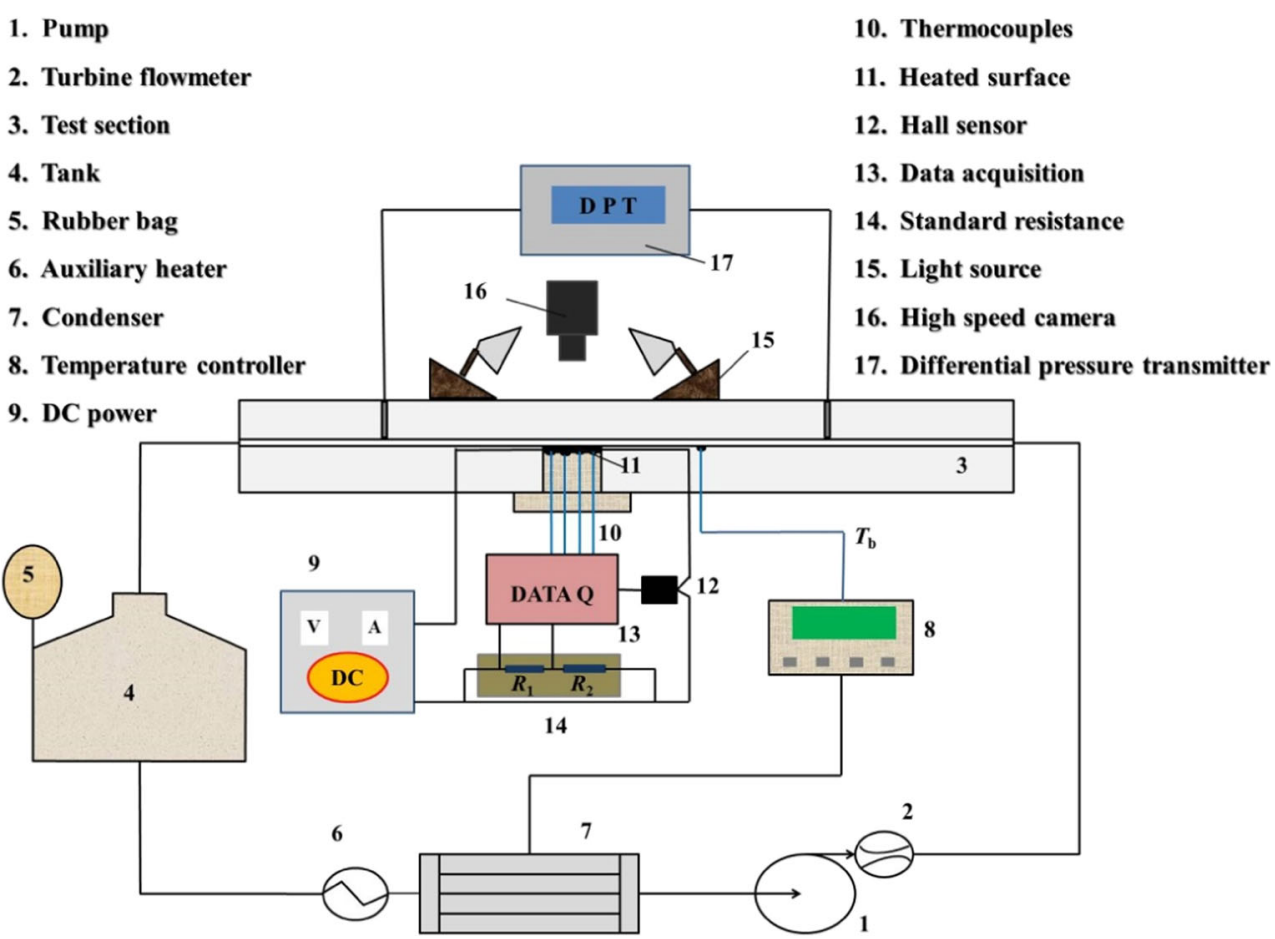

1. Pump

2. Turbine flowmeter

3. Test section

7. Condenser

9. DC power
Thermocouples

12. Hall sensor

Data acquisition

Standard resistance

15. Light source

16. High speed camera

17. Differential pressure transmitter chip was a $\mathrm{P}$ doped $\mathrm{N}$-type silicon chip with the resistivity of 1-3 $\Omega \cdot \mathrm{cm}$, and thus the heater was based on Joule heating under the application of DC power. The distance from the heater to the inlet of rectangular channel is 60 times greater than the hydraulic diameter $\left(D_{\mathrm{h}}=4.8 \mathrm{~mm}\right)$; therefore, the flow state on the heater can be regarded as fully developed turbulent flow. As illustrated in Fig. 2a, the silicon chip was connected to a programmable DC power supply by using two $0.25 \mathrm{~mm}$ diameter copper wires that were soldered to the side surfaces of test chip at the opposite ends by using ultrasonic welder (SUNBONDER USM-5). The test chip was bonded onto a plexiglass plate by using adhesive with thermal insulating glue (MOMENTIVE RTV-108, $k=0.12 \mathrm{~W} \cdot \mathrm{m}^{-1} \cdot \mathrm{K}^{-1}$ ) to minimize heat loss. Next, the chip unit was packaged in the plexiglass base through the use of a thicker layer of heat insulation glue (as shown in Fig. 2b). Therefore, it can be considered that the heat transfer only occurs effectively on the upper surface of the test chip. Figure $2 \mathrm{c}$ shows the details of chip unit. Four $0.15 \mathrm{~mm}$ diameter T-type thermocouples for wall temperature measurements were attached to the back of the test chip by thermal conductive adhesive, each separated by the same distance of $10 \mathrm{~mm}$.

A high-speed digital camera (VITcam CTC) with a lens (ComputarMLM-3XMP) operating at 1000 frames per second, at a resolution of $512 \times 1280$ pixels was used for visualization. Simultaneously, four $25-\mathrm{Hz}$ CCD cameras were installed in front of the display panel of turbine flowmeter, differential pressure transmitter, high-speed camera and temperature controller to monitor the operational state of the test system. Two standard resistances in series $\left(R_{1}=5 \mathrm{k} \Omega\right.$ and $R_{2}=100 \mathrm{k} \Omega$ ) connected to the test chip in parallel were used to measure the heating voltage $\left(U_{\mathrm{H}}\right)$ across the silicon chip in the circuit, and the heating current $\left(I_{\mathrm{H}}\right)$ through the silicon chip was measured by a hall senor. The gravity level was obtained by a gravity acceleration sensor. Ultimately, the wall temperature $\left(T_{1}\right.$ $\left.T_{4}\right)$, the pressure drop $(\Delta P)$, the heating voltage $\left(U_{\mathrm{H}}\right)$ and the heating current $\left(I_{\mathrm{H}}\right)$ were transmitted to a data acquisition system (DI710-UHS). In the present study, the data acquisition system (DI710-UHS) can only collect voltage signal with $0-5 \mathrm{~V}$. Before conducting experiment in the drop tower, the calibration experiments were performed. The circuit principle and the diagram of acquisition system are shown in Fig. 3. A standard resistance, $R=250 \Omega$, was used to measure the voltage across the hall sensor, and two standard resistances in series $\left(R_{1}=5 \mathrm{k} \Omega\right.$ and $R_{2}=100 \mathrm{k} \Omega$ ) connected to the test chip in parallel were used to measure the heating voltage $\left(U_{\mathrm{H}}\right)$ across the silicon chip, and thus the voltage signal across the silicon chip can be converted to 05V. Finally, the calibration correlations can be expressed as follows:

$I_{\mathrm{H}}=0.15966 U_{\mathrm{Hall}}-0.01895$

$U_{\mathrm{H}}=21.25756\left(U_{1}-0.0059\right)$

and the calibration curves are shown in Fig. 4. 
Fig. 2 Schematic diagram of the test section: a Test chip Soldering, b Chip heating module, and $\mathbf{c}$ Chip unit

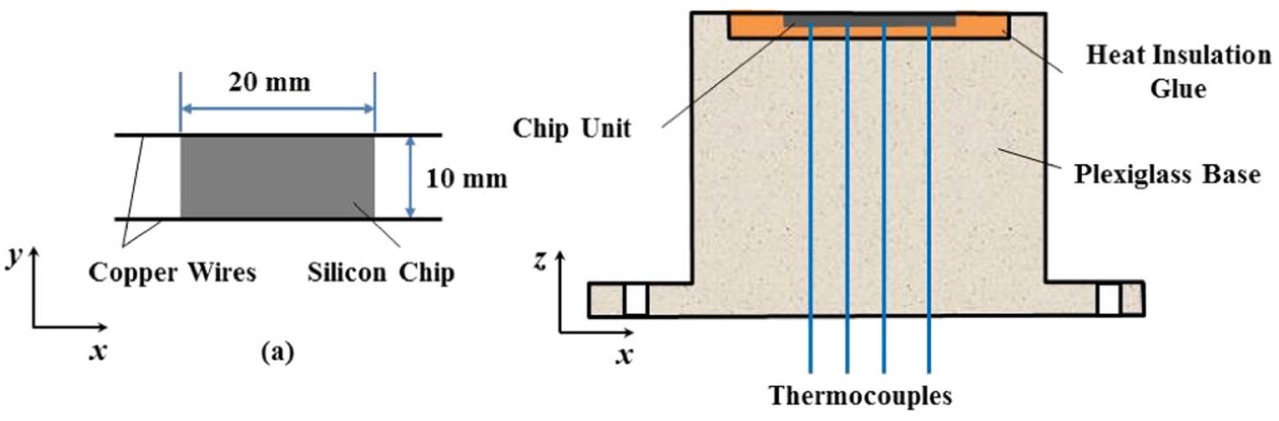

(b)

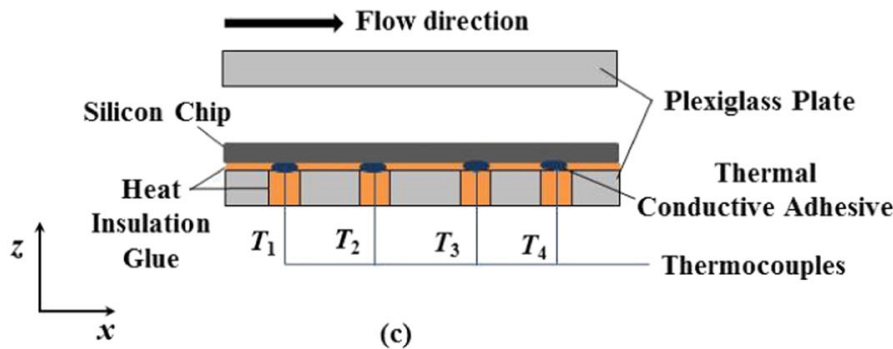

\section{Test Procedures}

In the present study, FC-72 was chosen as the working fluid without degasification processing because a previous study (Zhang et al. 2014) proved that the existence of noncondensable gas merely influences the onset of nucleate boiling, whereas the heat fluxes of this study are much higher than that at the onset of nucleate boiling. The inlet liquid velocity, $V=0.5 \mathrm{~m} / \mathrm{s}$ corresponding the mass velocity $G=815.7 \mathrm{~kg} / \mathrm{m}^{2} \cdot \mathrm{s}$, was chosen. The flow boiling heat transfer and bubble behavior on a smooth surface (chip S) were studied in microgravity by utilizing the drop tower facility in the CAS Key Laboratory of Microgravity. The microgravity level $(\mu g)$ is approximately $10^{-2} \sim 10^{-3} g_{0}$ in the free-falling period, where $g_{0}$ is gravitational acceleration in terrestrial condition. The working fluid in the pipeline was heated to $41{ }^{\circ} \mathrm{C}$ before the test chip was heated. Next, the test chip was heated under a set constant input voltage to
Fig. 3 The circuit principle and the diagram of acquisition system

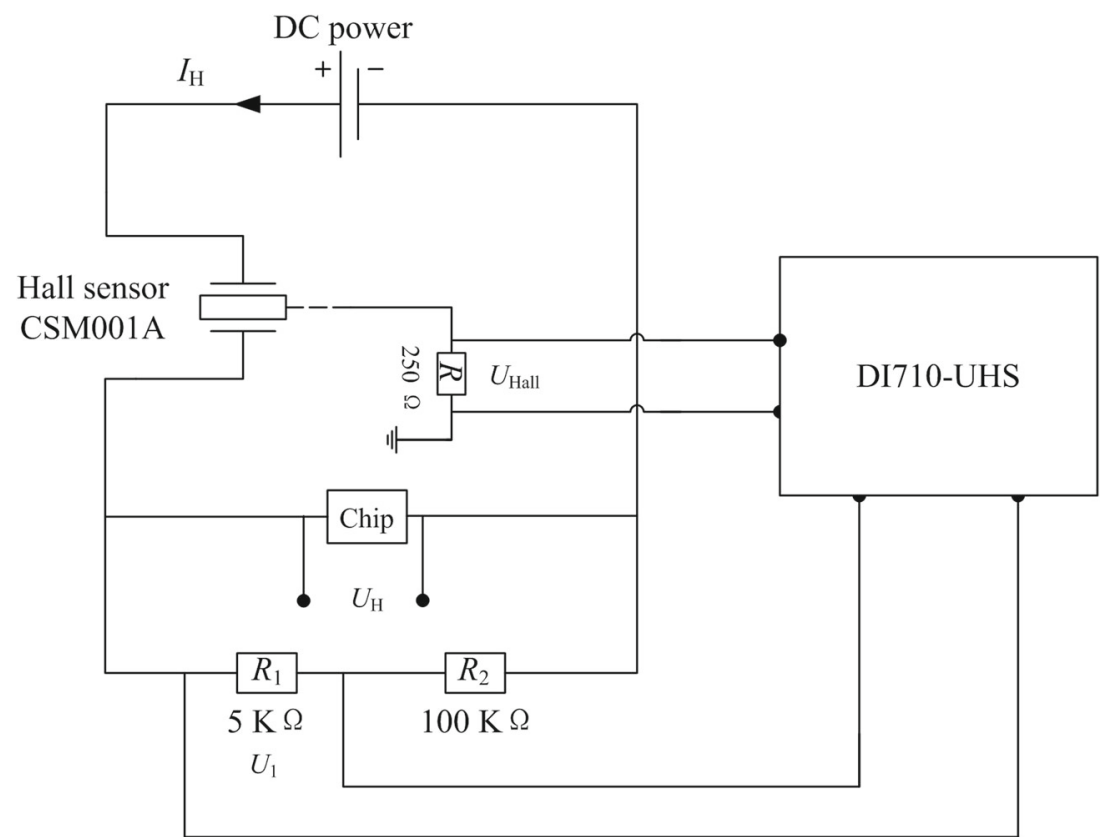



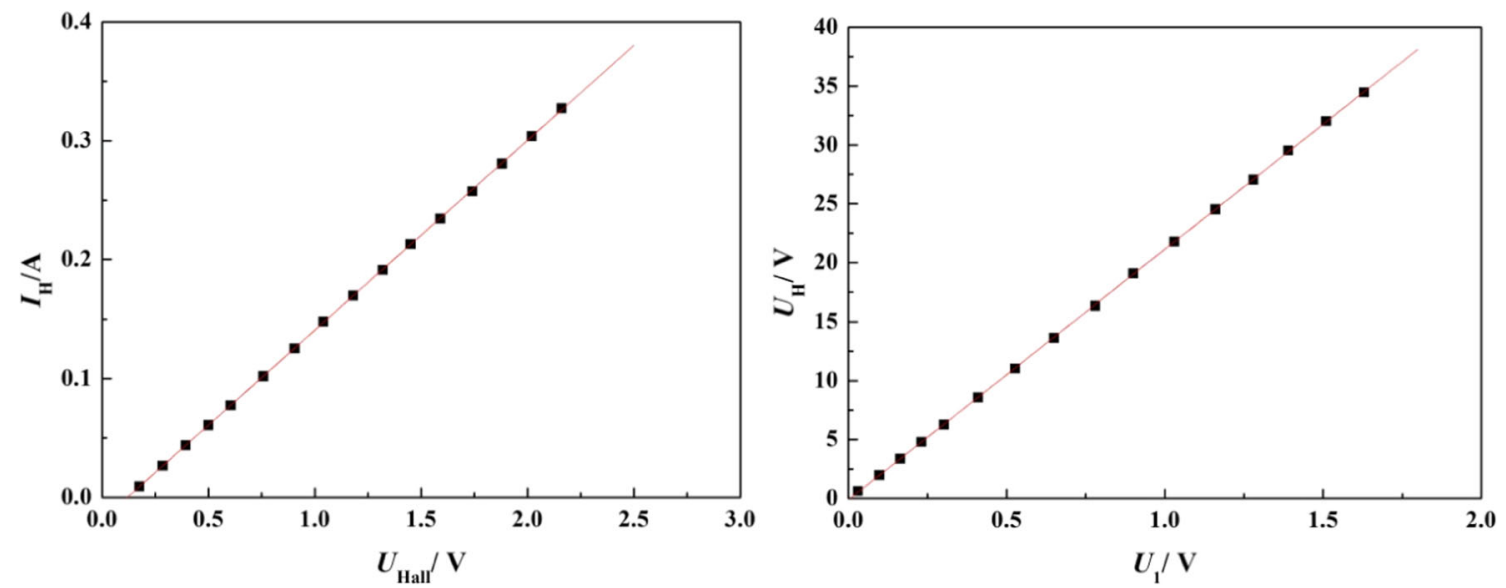

Fig. 4 The calibration curves of $U_{\mathrm{H}}$ and $I_{\mathrm{H}}$

initiate boiling on the heater wall in terrestrial gravity before the release of drop capsule, and the heat transfer reached a steady state after $2.5 \mathrm{~min}$ approximately. Afterwards, the drop capsule was released to achieve a $3.6 \mathrm{~s}$ effective microgravity environment. During the process, the bubble behavior on the heated surface was captured by the highspeed camera before and after the release of the drop capsule for $4.096 \mathrm{~s}$, the period of observation was divided into two parts according to the gravity acceleration signal: the first section $(0.205 \mathrm{~s})$ is in terrestrial gravity before release, whereas the second section (3.891 s) is in microgravity after release. Note that the experiment for each heat flux was conducted with only one test run because of the limitation of experimental resources. To ensure the reproducibility and reliability of the experimental data, experiments of flow boiling heat transfer in terrestrial gravity were also conducted for comparison. Table 1 shows the detailed experimental conditions of a smooth surface in microgravity at $V=0.5 \mathrm{~m} / \mathrm{s}$.

\section{Uncertainty Analysis}

In this study, the uncertainty of platinum resistance thermometer is $0.23^{\circ} \mathrm{C}$. As shown in Table 1, the maximum experimental operation error of liquid temperature is $0.3^{\circ} \mathrm{C}$. The minimum temperature of the working liquid is $40.5^{\circ} \mathrm{C}$. Therefore, the uncertainty of liquid temperature is $1.4 \%$. In addition, the error of the wall temperature of the heater is $0.3{ }^{\circ} \mathrm{C}$, and its uncertainty is approximately $0.73 \%$. The input heat flux of heater can be calculated as

$q=\frac{U_{\mathrm{H}} \cdot I_{\mathrm{H}}}{L \cdot b}$

where $L$ and $b$ represent the length and width of heater, respectively. The uncertainty of input heat flux $(\Delta q)$ mainly originates from the uncertainty of the error of the heating voltage and the heating current as well as the tolerance of silicon chip manufacturing. The uncertainty of heat flux can be calculated as

$$
\frac{\Delta q}{q}=\left(\left(\frac{\Delta U_{\mathrm{H}}}{U_{\mathrm{H}}}\right)^{2}+\left(\frac{\Delta I_{\mathrm{H}}}{I_{\mathrm{H}}}\right)^{2}+\left(\frac{\Delta L}{L}\right)^{2}+\left(\frac{\Delta b}{b}\right)^{2}\right)^{1 / 2}
$$

where $\Delta U_{\mathrm{H}}, \Delta I_{\mathrm{H}}, \Delta L$ and $\Delta b$ are the error of the heating voltage, the heating current, the length of the heater and the width of the heater, respectively. In this article, the measurement uncertainties for $\Delta U_{\mathrm{H}} / U, \Delta I_{\mathrm{H}} / I, \Delta L / L$, and $\Delta b / b$ are $0.1 \%, 0.14 \%, 0.5 \%$ and $0.5 \%$, respectively. For $U_{\mathrm{H}}$ and $I_{\mathrm{H}}$, the reality values were measured by Agilent voltmeter and ammeter, and the measured values were calculated based on Eqs. 1 and 2. Besides, the uncertainties of $L$ and $b$ are caused by processing error. The total heat loss $\Delta q_{\text {tot }}$ comprises the uncertainty of the input heat flux $(\Delta q)$, the heat loss through substrate conduction $\left(\Delta q_{\text {con }}\right)$ and the
Table 1 Experimental conditions of chip $\mathrm{S}$ in microgravity at $V=0.5 \mathrm{~m} / \mathrm{s}$

\begin{tabular}{lllll}
\hline Run\# & Subcooling $\Delta T_{\text {sub }}(\mathrm{K})$ & Heating voltage $U_{\mathrm{H}}(\mathrm{V})$ & Heating current $I_{\mathrm{H}}(\mathrm{A})$ & Heat flux $q\left(\mathrm{~W} / \mathrm{cm}^{2}\right)$ \\
\hline $1 \#$ & 14.8 & 17.1 & 1.69 & 7.2 \\
$2 \#$ & 14.9 & 21.8 & 2.10 & 11.4 \\
$3 \#$ & 14.7 & 23.7 & 2.25 & 13.3 \\
$4 \#$ & 14.8 & 28.0 & 2.59 & 18.2 \\
$5 \#$ & 14.7 & 31.5 & 2.70 & 21.3 \\
\hline
\end{tabular}


heat loss of the fluctuation of volume flow rate $\left(\Delta q_{\mathrm{V}}\right)$. The uncertainty of total ratio of heat loss is calculated as

$\frac{\Delta q_{\mathrm{tot}}}{q}=\frac{\Delta q}{q}+\frac{\Delta q_{\mathrm{con}}}{q}+\frac{\Delta q_{\mathrm{V}}}{q}$

According to the heat loss simulation results of O'Connor and You (1995), the ratio of heat loss through substrate conduction $\Delta q_{\mathrm{con}} / q$ is approximately $5.0 \%$. The fluctuation of the volume flow rate during the experiment (maximum fluctuation of volume flow rate is approximately 7.0\%) can also influence the critical heat flux. According to the experimental results in normal gravity, the uncertainty caused by the fluctuation of volume flow rate $\Delta q_{\mathrm{V}} / q$ is approximately $0.8 \%$. Here, the repeatability experiment was performed three times, thus the uncertainty, $\Delta q_{\mathrm{V}} / q$, between measured and averaged values of heat flux caused by the fluctuation of volume flow rate can be calculated. Thus, the uncertainty of heat flux is less than $7.0 \%$.

\section{Results and Discussion}

\section{Heat Transfer Performance}

Figure 5 shows the pool and flow boiling curves of smooth surface at different gravity levels. $\Delta T_{\text {sat }}$ represents the wall superheat which is the difference between $T_{\mathrm{w}}$ and $T_{\text {sat }}$. Figure 6 shows the average wall temperature measured by four thermocouples ( $T_{1 \text {-ave }}, T_{2 \text {-ave }}, T_{3-\text { ave }}$ and $\left.T_{4-\text { ave }}\right)$ at different gravity levels for all the run tests except for the last unsteady point at inlet velocity $V=$ $0.5 \mathrm{~m} / \mathrm{s}$, respectively Meanwhile $T_{1 \text {-ave }}, T_{2 \text {-ave }}, T_{3 \text {-ave }}$ and $T_{4-a v e}$ at different gravity levels are calculated by the arithmetic mean of the data during the normal gravity period of $-4-0 \mathrm{~s}$ before release and microgravity period of
$0-3.6 \mathrm{~s}$ after release. Moreover, $T_{\mathrm{w}}$ is the average value of wall temperatures measured by four thermocouples ( $\left.\left(T_{1 \text {-ave }}+T_{2 \text {-ave }}+T_{3 \text {-ave }}+T_{4 \text {-ave }}\right) / 4\right)$, and $T_{\text {sat }}$ is the saturation temperature of working fluid. As shown in Table 1, five run tests under microgravity conditions were conducted at five different heat fluxes $\left(7.2 \mathrm{~W} / \mathrm{cm}^{2}, 11.5 \mathrm{~W} / \mathrm{cm}^{2}\right.$, $13.3 \mathrm{~W} / \mathrm{cm}^{2}, 18.2 \mathrm{~W} / \mathrm{cm}^{2}$, and $21.3 \mathrm{~W} / \mathrm{cm}^{2}$ ), respectively. For comparison, the experimental results of pool boiling on a smooth silicon chip in microgravity conducted by Xue et al. (2011) are also listed.

As shown in Fig. 5, two heat transfer regions are marked as low and moderate heat fluxes region and high heat flux region. In the low and moderate heat fluxes region under normal gravity and microgravity, flow boiling and pool boiling with smooth surface show similar trends, that the heat transfer is slightly enhanced in microgravity. From Fig. 6a, it can be seen clearly that the wall temperature increases along the flow direction at a constant heat flux in the low and moderate heat fluxes region $\left(7.2 \mathrm{~W} / \mathrm{cm}^{2}, 11.5 \mathrm{~W} / \mathrm{cm}^{2}\right.$, and $\left.13.3 \mathrm{~W} / \mathrm{cm}^{2}\right)$, and almost all the wall temperatures at different positions in microgravity are slightly lower than that in normal gravity, which indicates slight heat transfer enhancement. The lowest wall temperature $T_{1 \text {-ave }}$, at different heat fluxes are attributed to the fluid entering the heated region as subcooled liquid at the lowest temperature. The wall temperature initially increases downstream as a result of both gradual rise in liquid temperature and vapor layer development. This trends are quite different from the results of flow boiling experiments of subcooled FC-72 in a vertical rectangular channel $(2.5 \mathrm{~mm} \times 5 \mathrm{~mm} \times 114.6 \mathrm{~mm}$, width $\times$ height $\times$ length) with single-sided heating wall at liquid inlet velocities of $0.1-1.9 \mathrm{~m} / \mathrm{s}$ conducted by Konishi et al. (2015a). They found that for a fixed heat flux, the wall temperature increases from the leading edge of the
Fig. 5 Pool and flow boiling curves of chip $\mathrm{S}$ at different gravity levels

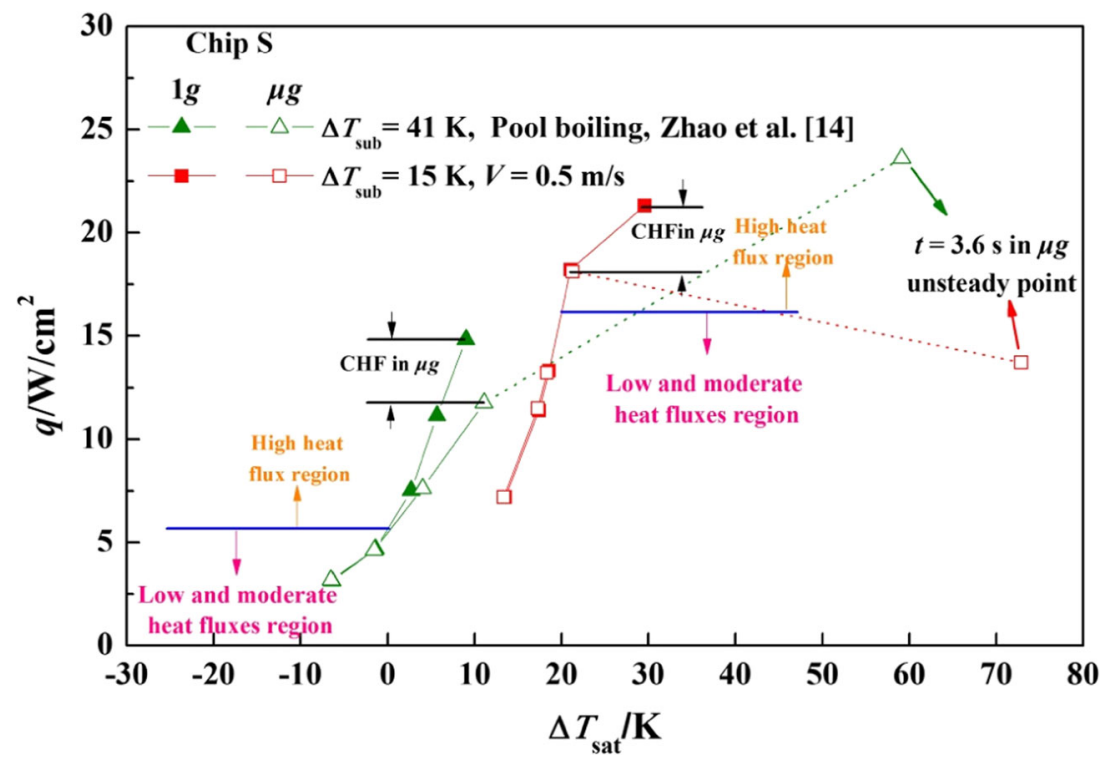




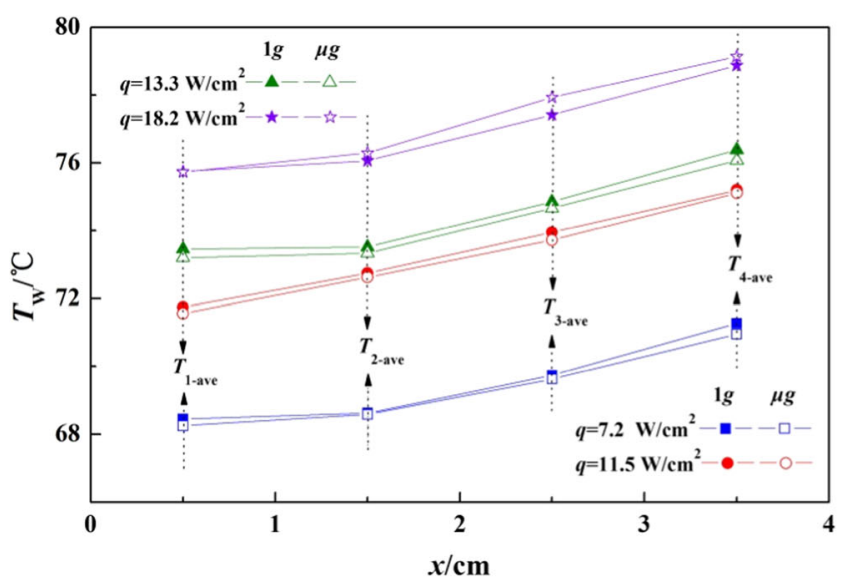

(a) The data in the present study

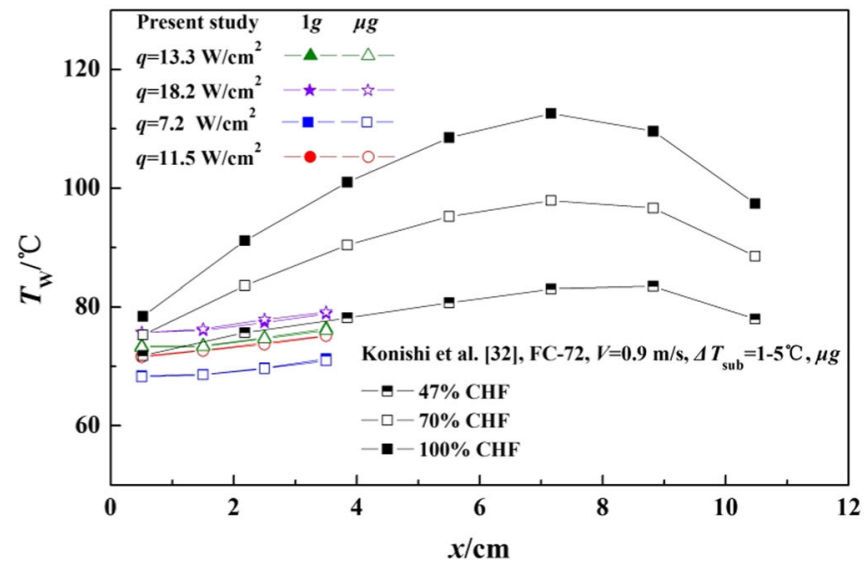

(b) Comparison with the data of Konishi et al. [32]

Fig. 6 Wall temperatures along flow direction measured by four thermocouples at different gravity levels

heated wall to a maximum immediately downstream from the middle, before decreasing again toward the exit. For the first stage of increasing from the leading edge of the heated wall to a maximum, it is attributed to the same reason mentioned above. While for the second stage of decreasing again toward the exit, they pointed that the vapor generation also causes gradual acceleration of the flow, which is good for enhancing heat transfer and therefore decreases wall temperature. The net effect of these two opposing trends is to achieve maximum wall temperature shortly downstream of the middle, before acceleration dominates heat transfer and reduces wall temperature toward the exit. However, we did not find the second stage in our experiment, and there are two possible reasons. The first one is that the length of the heater and the height of the channel of Konishi et al. (2015a) are larger than that in our experiment, and it can provide enough distance and space to develop to the second stage mentioned above. Secondly, we can see that the increment of wall temperature of Konishi et al. (2015a) in Fig. 4b is larger than that in our experiment. It is might be attributed that the liquid subcooling of Konishi et al. (2015a) is lower than that in the present study. Furthermore, the vapor layer is more easily to develop along the heater surface in vertical channel. But for the horizontal channel in the present study, the microgravity level $(\mu g)$ is approximately $10^{-2} \sim 10^{-3} g_{0}$, and the buoyancy force is still working. Therefore, the vapor layer development is not as fast as in vertical channel. Thus, the effect of microgravity on vertical flow and horizontal flow is slightly different.

In the high heat flux region, much evident deterioration of heat transfer can be observed in microgravity for pool boiling
Fig. 7 Wall temperatures at different gravity levels at inlet velocity $V=0.5 \mathrm{~m} / \mathrm{s}$

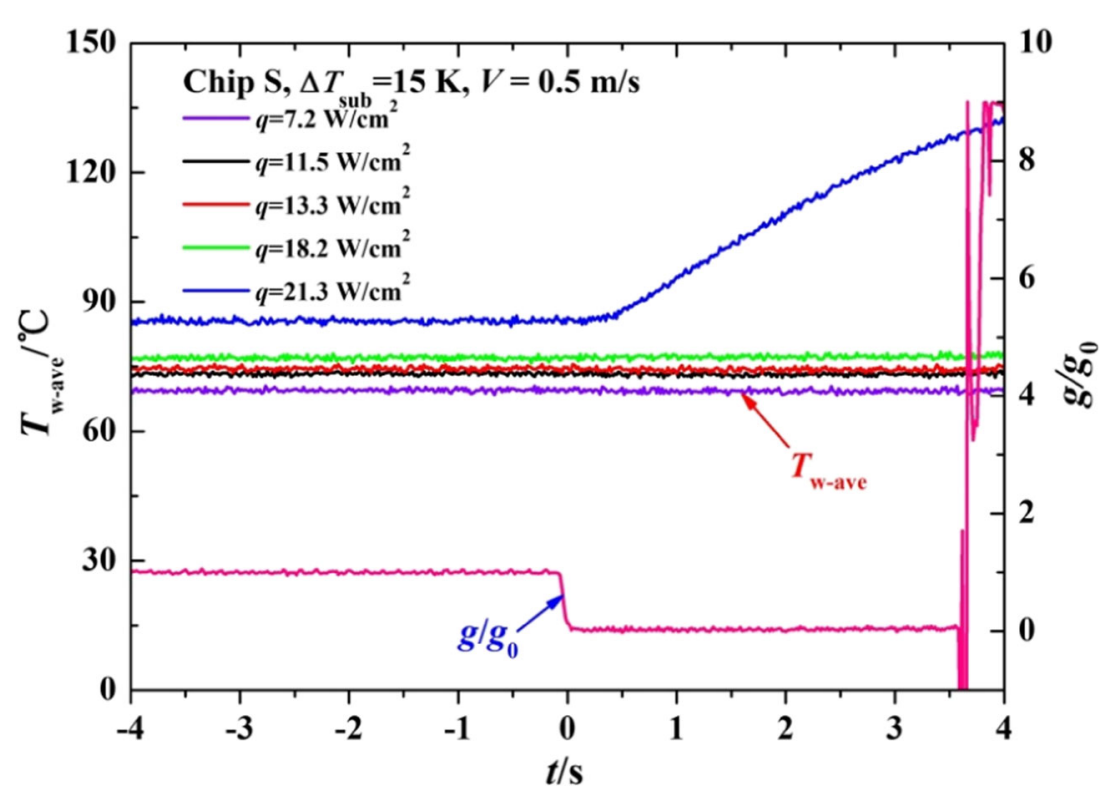


of chip $\mathrm{S}$ in microgravity as shown in Fig. 5. The reason for the general increase in the mean heater surface temperature of pool boiling heat transfer is that the coalesced large bubble with large contact area on the heater surface can not depart from the heater surface and gradually dryout at the bottom of the coalesced large bubble in microgravity. However, the flow boiling of smooth surface in microgravity only shows slight deterioration of heat transfer, such as $q=18.2 \mathrm{~W} / \mathrm{cm}^{2}$ shown in Figs. 5 and 6. This is attributed to that the inertia force can take the bubbles away from the heater surface much easier than that of pool boiling.

Generally, the flow boiling of smooth surface at inlet velocity $V=0.5 \mathrm{~m} / \mathrm{s}$ shows almost the same regulations as pool boiling in the low and moderate heat fluxes region that all the wall temperatures at different positions in microgravity are slightly lower than that in normal gravity, which indicates slight heat transfer enhancement. While the pool boiling of smooth surface shows much evident deterioration of heat transfer compared with that of flow boiling in the high heat flux region. In addition, the flow boiling of smooth surface at inlet velocity $V=0.5 \mathrm{~m} / \mathrm{s}$ shows higher $\mathrm{CHF}$ than that of pool boiling, which is mainly due to the inertia force. Obviously, the HTC of the entire pool boiling heat transfer process is lower than that of flow boiling. The main reason is that the liquid subcooling of pool boiling is $41 \mathrm{~K}$, which is much larger than that of flow

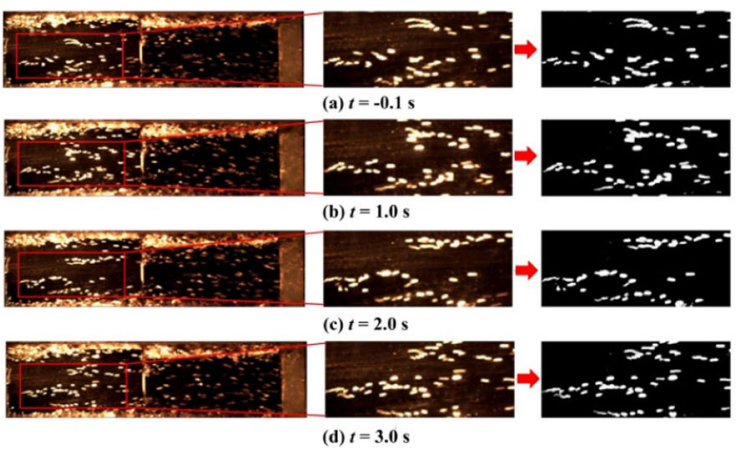

(a) $q=7.2 \mathrm{~W} / \mathrm{cm}^{2}$

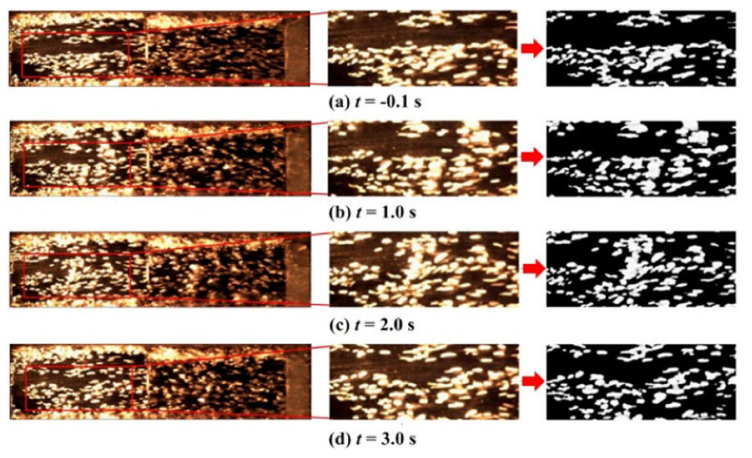

(b) $q=11.5 \mathrm{~W} / \mathrm{cm}^{2}$

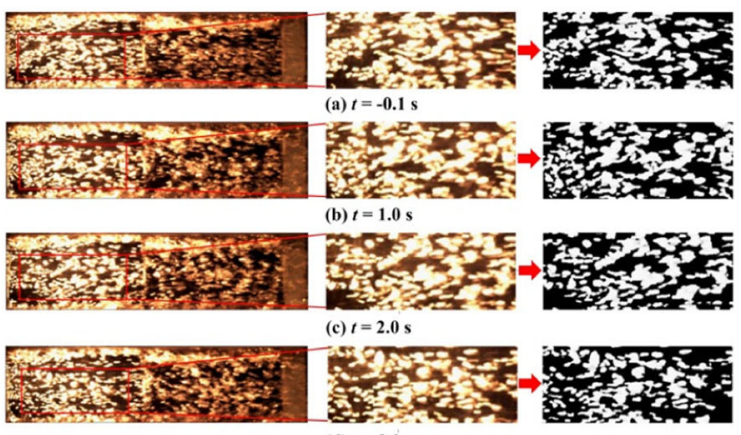

(d) $t=3.0 \mathrm{~s}$

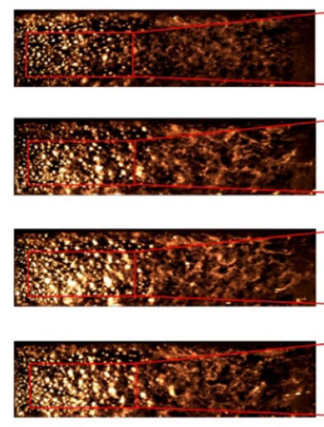

(d) $q=18.2 \mathrm{~W} / \mathrm{cm}^{2}$

(c) $q=13.3 \mathrm{~W} / \mathrm{cm}^{2}$

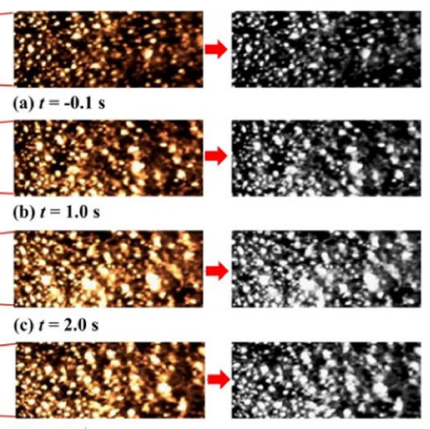

(d) $t=3.0 \mathrm{~s}$

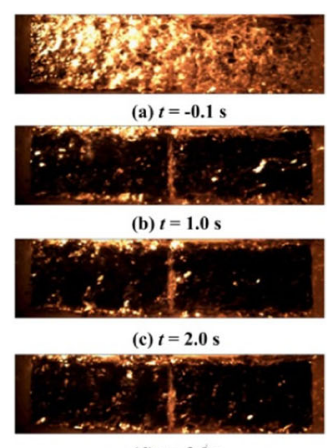

(d) $t=3.0 \mathrm{~s}$

(e) $q=21.3 \mathrm{~W} / \mathrm{cm}^{2}$

Fig. 8 Visualization images at different gravity levels at inlet velocity $V=0.5 \mathrm{~m} / \mathrm{s}$ 
boiling. Moreover, forced convection combined nucleate boiling dominant the heat transfer process, so the HTC is lower than that of pure nucleate boiling.

\section{Bubble Behaviors}

The mean wall temperature $\left(T_{\mathrm{w}-\mathrm{ave}}=\left(T_{1}+T_{2}+T_{3}+\right.\right.$ $\left.T_{4}\right) / 4$ ) and bubble behaviors corresponding to heat fluxes of $7.2 \mathrm{~W} / \mathrm{cm}^{2}, 11.5 \mathrm{~W} / \mathrm{cm}^{2}, 13.3 \mathrm{~W} / \mathrm{cm}^{2}, 18.2 \mathrm{~W} / \mathrm{cm}^{2}$ and $21.3 \mathrm{~W} / \mathrm{cm}^{2}$ at different gravity levels at inlet velocity $V=$ $0.5 \mathrm{~m} / \mathrm{s}$ are shown in Figs. 7 and 8, respectively. It should be noted that the time entering microgravity condition was set to $0 \mathrm{~s}$, and flow boiling was in the stage of normal gravity when $t<0$, while $t>0$ means in the stage of microgravity.

In the low and moderate heat fluxes region $\left(7.2 \mathrm{~W} / \mathrm{cm}^{2}\right.$, $11.5 \mathrm{~W} / \mathrm{cm}^{2}, 13.3 \mathrm{~W} / \mathrm{cm}^{2}$ ), it is clearly to see from Fig. 7 that the mean wall temperature $\left(T_{\mathrm{w}-a v e}\right)$ remains nearly constant both in normal gravity and microgravity conditions. This indicates that the reduction of gravity does not deteriorate the heat transfer but slightly enhance the performance in the low heat flux region (as shown detailed in Fig. 6). Figure 8a and e shows the visualization images at different gravity levels at inlet velocity $V=0.5 \mathrm{~m} / \mathrm{s}$. In normal gravity, for $q=7.2 \mathrm{~W} / \mathrm{cm}^{2}$ as shown in Fig. 8a, only a few nucleation sites are activated $(t=-0.1 \mathrm{~s})$. The small bubbles are driven along the heated wall by liquid shear and drag forces, and grow in size because of further evaporation as well as coalescence with other bubbles. With increasing heat flux, more nucleation sites are activated and more bubbles can be found. Besides, bubble coalescence behaviors become much vigorous from inlet to downstream along the flow direction, as shown in Fig. 8be. After entering microgravity, for $q=7.2,11.5$, and $13.3 \mathrm{~W} / \mathrm{cm}^{2}$, coalesced bubbles become larger than that in normal gravity due to the absence of buoyancy. With time increasing from $1.0 \mathrm{~s}$ to $3.0 \mathrm{~s}$ in microgravity as shown in Fig. $8 \mathrm{a}-\mathrm{c}$, there is no obvious change in bubble behavior. In the high heat fluxes region with increasing heat flux to $18.2 \mathrm{~W} / \mathrm{cm}^{2}$, it can be seen in Fig. 7 that the mean wall temperature is still constant in both normal gravity and microgravity conditions, and only slightly increases in microgravity (as shown detailed in Fig. 6). At this heat flux, the vapor bubbles number significantly increases in both normal gravity and microgravity, and coalescence occurs continuously among adjacent bubbles which become vigorous and frequent in microgravity. The size of coalesced bubbles increases gradually with time increasing from 1.0 to $3.0 \mathrm{~s}$ in microgravity as shown in Fig. 8d. This is because more nucleation sites are activated at high heat flux, and small bubbles coalesce with each other easily in the absence of buoyancy. The upstream activity quickly coalesces with each other and develops into large vapor patches in the downstream of heater surface as shown in
Fig. 8d. However, the inertia force can still take these vapor patches away. Thus, the steady state boiling heat transfer can be maintained. With further increasing heat flux to $21.3 \mathrm{~W} / \mathrm{cm}^{2}$, the wall temperature remains constant before release but increases quickly after entering microgravity, indicating heat transfer crisis occurs as shown in Fig. 7. As for the bubble behavior, many large vapor patches can be found in normal gravity as shown in Fig. 8e. While the large vapor patches can still be taken away by the inertia force of fluid, and thus shows the steady boiling heat transfer. However, the bubble flow transits to wavy flow quickly along the whole heated wall after entering microgravity $(t=1.0 \mathrm{~s})$, and the whole heater is covered by the vapor As a result, no fresh liquid can be supplied to heater surface for evaporation, and the corresponding wall temperature increases sharply. Finally, the CHF occurs.

For further analysis, a fixed region is chosen for analysis as marked by red outline as shown in Fig. 8. The method of picture binarization by MATLAB was used, and the bubble shape profile can be detected clearly. Although the size and number of the bubbles can not be calculated accurately, the ratio of total area of bubbles to the fixed region marked by red outline (total area of bubbles and fluid), $A_{\text {bubble }} / A_{\text {bubble+fluid }}$, can be calculated exactly based on binarization image by statistical method. Generally, the $A_{\text {bubble }} / A_{\text {bubble+fluid }}$ can represent the overall size change of bubbles before and after entering microgravity in $x-y$ plane, and also represent the void fraction in $x-y$ plane, $\alpha_{x-y}$, captured by camera from the top view of channel (not an accurate void fraction in a fixed $x-y$ plane in the flow channel). As shown in Fig. 9, the average values of $\alpha_{x-y}$ during the normal gravity period of $-0.205-0 \mathrm{~s}$ before release and microgravity period of $0-3.6 \mathrm{~s}$ after release at $q=7.2 \mathrm{~W} / \mathrm{cm}^{2}, 11.5 \mathrm{~W} / \mathrm{cm}^{2}, 13.3 \mathrm{~W} / \mathrm{cm}^{2}$ and $18.2 \mathrm{~W} / \mathrm{cm}^{2}$

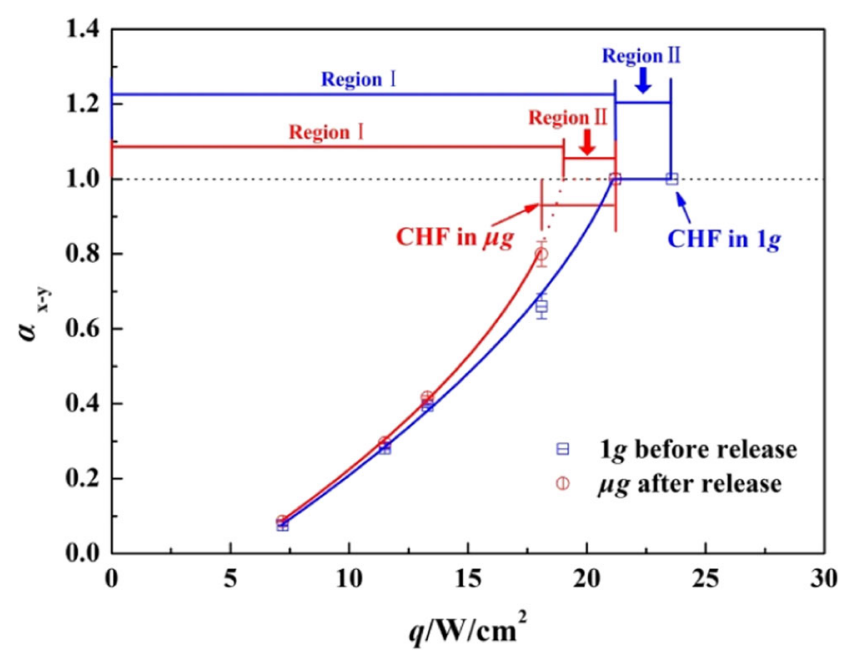

Fig. 9 Void fraction in $x-y$ plane, $\alpha_{x-y}$, captured by camera from the top view of channel at different gravity levels 
Fig. 10 CHF results at different gravity levels at inlet velocity $V=0.5 \mathrm{~m} / \mathrm{s}$

Fig. 11 Bubble behaviors of heat transfer crisis at different gravity levels at $q=21.3 \mathrm{~W} / \mathrm{cm}^{2}$

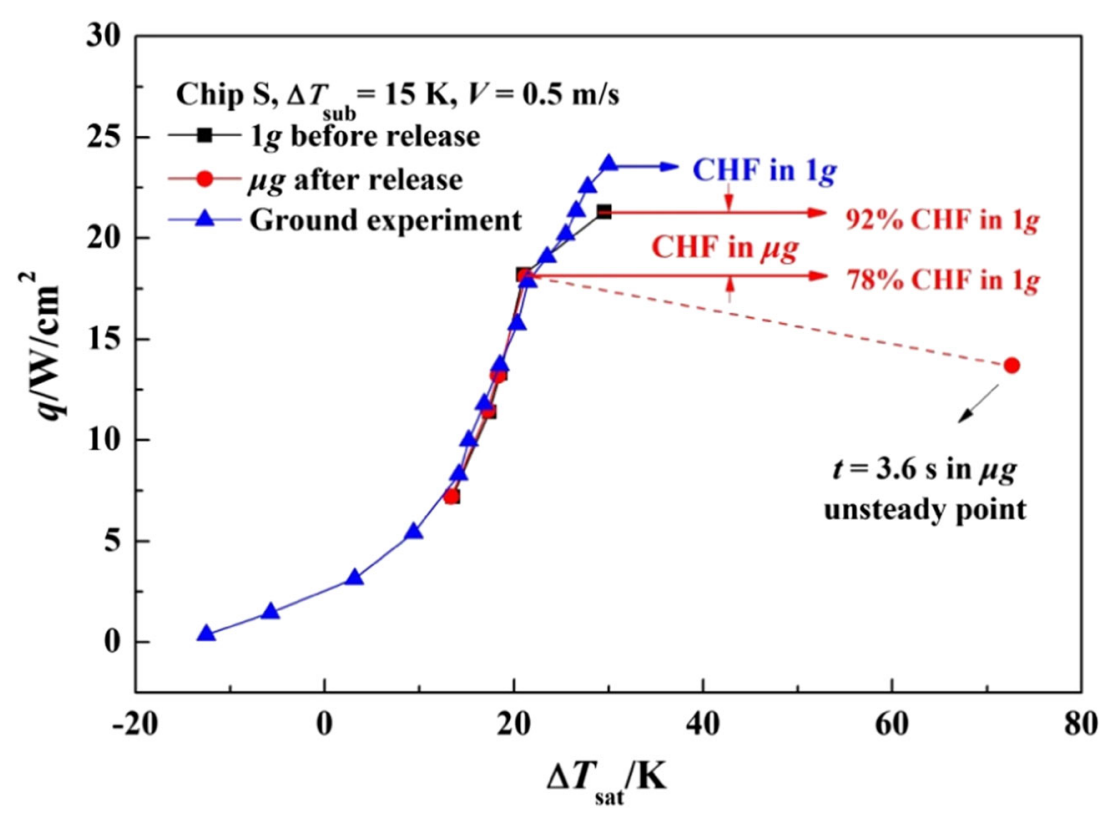

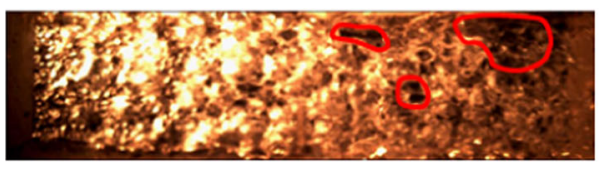

(a) $t=-0.1 \mathrm{~s}$

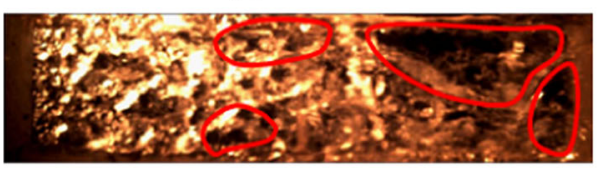

(c) $t=0.05 \mathrm{~s}$

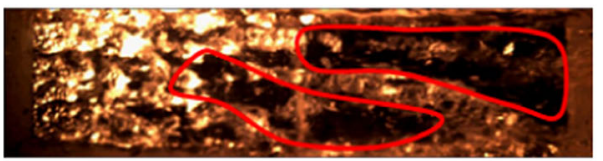

(e) $t=0.15 \mathrm{~s}$

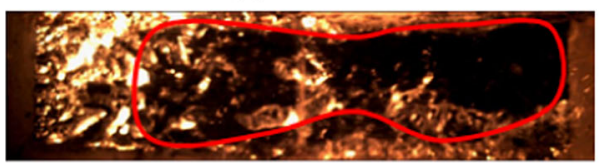

(g) $t=0.25 \mathrm{~s}$

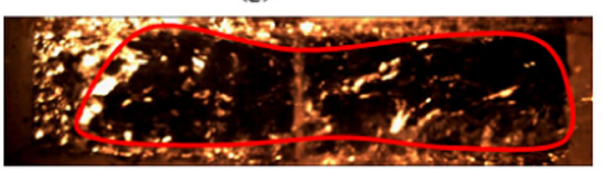

(i) $t=0.35 \mathrm{~s}$

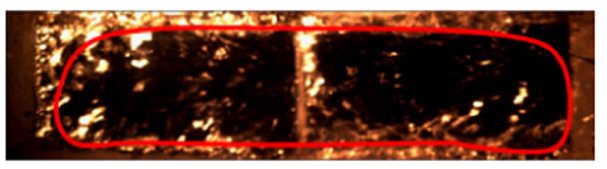

(k) $t=0.45 \mathrm{~s}$

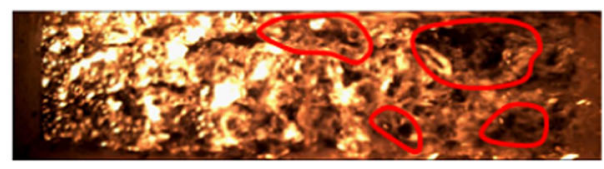

(b) $t=0.0 \mathrm{~s}$

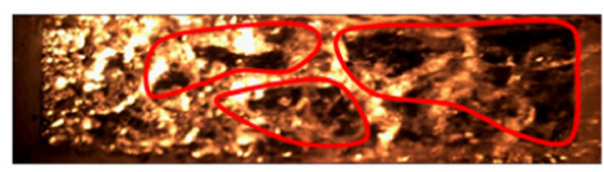

(d) $t=0.1 \mathrm{~s}$

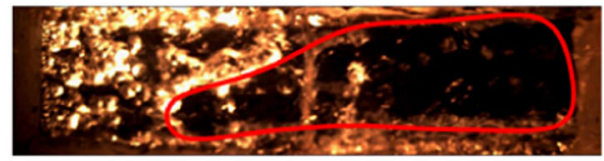

(f) $t=0.2 \mathrm{~s}$

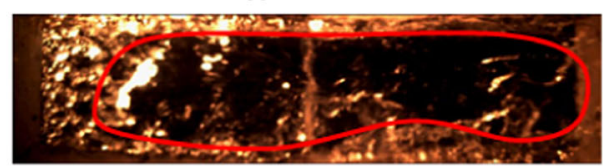

(h) $t=0.3 \mathrm{~s}$

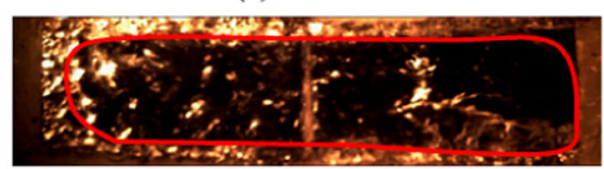

(j) $t=0.4 \mathrm{~s}$

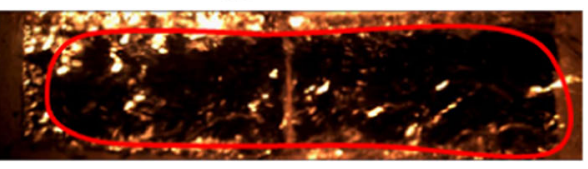

(1) $t=0.5 \mathrm{~s}$ 
are calculated, respectively. Correspondingly, the average values of $\alpha_{x-y}$ in normal gravity and microgravity are $7.5 \%$ and $8.6 \%, 28.1 \%$ and $29.5 \%, 39.5 \%$ and $41.7 \%$, and $66 \%$ and $80 \%$, respectively. This indicates that the bubbles after entering microgravity exactly become larger than that in normal gravity due to the lack of buoyancy For $q=$ $21.3 \mathrm{~W} / \mathrm{cm}^{2}$, the values of $A_{\text {bubble }} / A_{\text {bubble }+ \text { fluid }}$ are 1 in both microgravity and normal gravity according to the bubble behaviors as shown in Fig. 8e. It is interesting to found when $\alpha_{x-y}$ is larger than 1 , indicating the bubbles occupy the entire $x-y$ plane, the heat transfer can still maintain stable. So we divide the entire heat transfer process in both microgravity and normal gravity into two regions according to the values of $\alpha_{x-y}$ : region I $\left(\alpha_{x-y}<1\right)$ and region II $\left(\alpha_{x-y}=1\right)$. In the region I, the bubbles coalesce with each other and accumulate in the channel, and then occupy the entire $x$ - $y$ plane gradually with increasing heat flux. In this region, steady heat transfer can be maintained. In the region II, the bubbles have occupied the entire $x$ - $y$ plane, but CHF did not occur because there is still some space in $y-z$ plane of the channel. Once the bubbles occupy the entire $y$ - $z$ plane at the end of the heater the vapor blanket will be formed quickly and transmit from downstream to upstream along the heater, and CHF occurs. Thus, the height of flow channel has a significant effect on CHF.

\section{Critical Heat Flux and Heat Transfer Mechanisms}

Critical heat flux is a very important parameter for boiling heat transfer, especially for engineering application. Figure 10 shows $\mathrm{CHF}$ results at different gravity levels at inlet velocity $V=0.5 \mathrm{~m} / \mathrm{s}$. In this figure, the complete boiling curve on ground was obtained by the same experimental methods as in the drop tower before release, and it shows a good agreement with the data in the drop tower before release. From Fig. 10, it can be seen that the $\mathrm{CHF}$ of chip $\mathrm{S}$ with inlet velocity of $0.5 \mathrm{~m} / \mathrm{s}$ is $23.2 \mathrm{~W} / \mathrm{cm}^{2}$ under terrestrial gravity, and the $\mathrm{CHF}$ under microgravity is $18.2-21.3 \mathrm{~W} / \mathrm{cm}^{2}$ which is about $78-92 \%$ of that in normal gravity. Further analysis of bubble behaviors at CHF was performed as shown in Fig. 11. It shows the entire process of bubble behaviors of heat transfer crisis.
Fig. 12 Flow boiling heat transfer mechanisms in a horizontal rectangle channel
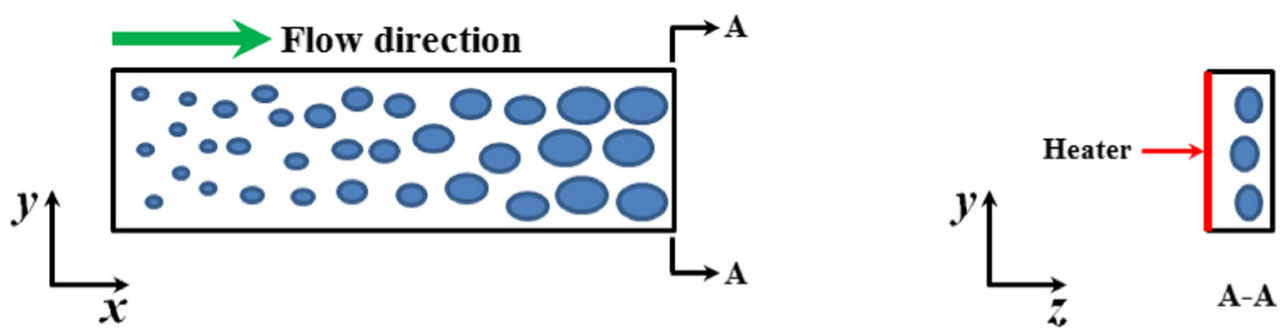

(a) $\alpha_{x-y}<1$ and $\alpha_{y-z}<1$
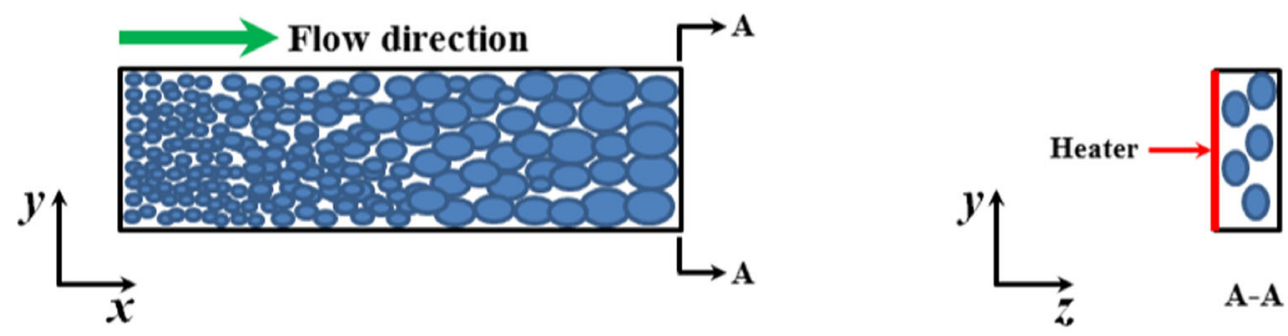

(b) $\alpha_{x-y}=1$ and $\alpha_{y-z}<1$
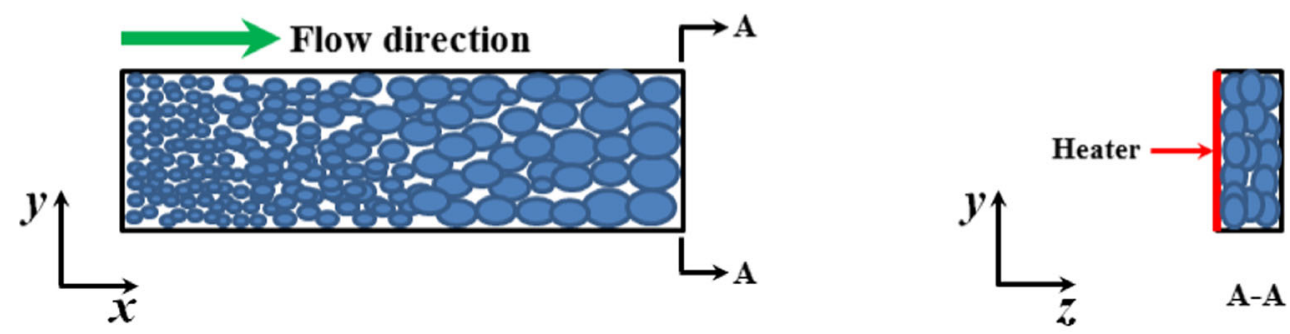

(c) $\alpha_{x-y}=1$ and $\alpha_{y-z}=1$ 
From Fig. 11a, it shows the bubble behaviors before entering in microgravity $(t=-0.1 \mathrm{~s})$ at $q=21.3 \mathrm{~W} / \mathrm{cm}^{2}$, and massive bubbles generate, coalescence and flow to the downstream, and thus small vapor patches are formed at the downstream. The wall temperature remains nearly a constant as shown in Fig. 7, and the small vapor patches can still be taken away by the inertia force of fluid, and thus shows the steady boiling heat transfer. While after entering in microgravity as shown in Fig. 11b-e, small vapor patches coalesce with each other to form the large vapor patches. Afterwards, the large vapor patches continue to coalesce with each other to form the vapor blanket with increasing time as shown in Fig. 11f-l. The bubble flow transits to wavy flow very quickly from downstream to upstream along the heater, and the corresponding wall temperature increases sharply as shown in Fig. 7. As a result, the whole heater is covered by the vapor, and no fresh liquid can be supplied to heater surface for evaporation. Finally, the CHF occurs.

Flow boiling heat transfer mechanisms in a horizontal rectangle channel are shown schematically in Fig. 12. From Fig. 12a, some isolated bubbles appear, and the bubbles in microgravity become larger than that in normal gravity due to the lack of buoyancy. In this situation $\alpha_{x-y}<1$ and $\alpha_{y-z}<1$, gravity shows nearly no effect on heat transfer performance and it covers the low and moderate heat fluxes region, because the inertia force can take the isolated bubbles away in time due to the small void fraction. In Fig. $12 \mathrm{~b}, \alpha_{x-y}=1$ and $\alpha_{y-z}<1$, the bubbles do not occupy the entire channel, especially at the end of the heater. In this situation, the inertia force can still take the bubbles away from the heater surface. In Fig. 12c $\alpha_{x-y}=1$ and $\alpha_{y-z}=1$, once void fraction $\alpha_{y-z}$ at the end of the heater equals 1 , the vapor blanket will be formed quickly and transmit from downstream to upstream along the heater, and thus CHF occurs. In microgravity, the void fraction $\alpha_{y-z}$ at the end of the heater is much easier to reach 1 than that in normal gravity due to relative large bubbles at the same heat flux. Thus, the height of flow channel determining $\alpha_{y-z}$ has a significant effect on $\mathrm{CHF}$ at a fixed velocity.

\section{Conclusions}

In this study, the flow boiling heat transfer on a smooth surface of subcooled air-dissolved FC-72 was investigated in normal gravity and microgravity. The main conclusions are listed as follows:

(1) The flow boiling of smooth surface at inlet velocity $V=0.5 \mathrm{~m} / \mathrm{s}$ shows almost the same regulations as pool boiling in the low and moderate heat fluxes region, which all the wall temperatures at different positions in microgravity are slightly lower than that in normal gravity, indicating heat transfer is enhanced. Without inertia force, the pool boiling of smooth surface shows much evident deterioration of heat transfer compared with the flow boiling in the high heat flux region.

(2) For the flow boiling of smooth surface at inlet velocity $V=0.5 \mathrm{~m} / \mathrm{s}$, the bubbles in microgravity exactly become larger than that in normal gravity due to lacking buoyancy, but show nearly no effect on heat transfer performance except for CHF.

(3) For the flow boiling heat transfer in microgravity, inertia force play a key role to control the heat transfer process. Obviously, the threshold velocity for the inertia-dominant flow boiling under different gravity conditions is larger than $0.5 \mathrm{~m} / \mathrm{s}$ in our experiment The CHF under microgravity is about $78-92 \%$ of that in normal gravity at $V=0.5 \mathrm{~m} / \mathrm{s}$.

(4) Flow boiling heat transfer mechanisms are summarized. When $\alpha_{x-y}<1$ and $\alpha_{y-z}<1$, gravity shows nearly no effect on heat transfer performance. When $\alpha_{x-y}=1$ and $\alpha_{y-z}<1$, the inertia force can still take the bubbles away from the heater surface. When $\alpha_{x-y}=1$ and $\alpha_{y-z}=1$, the vapor blanket will be formed and the bubble flow transits to wavy flow very quickly from downstream to upstream along the heater, and CHF occurs. Thus, the height of flow channel determining $\alpha_{y-z}$ has a significant effect on CHF at a fixed velocity.

Acknowledgements This work is supported by the project of National Natural Science Foundation of China (No. 51506169, No. 51636006, No. 51611130060), The Fundamental Research Funds For the Central Universities (No. cxtd2017004, xjj2017085), and the scientific research program for new lecturer of Xi'an Jiaotong University (No. DW010728K000000B), and China Postdoctoral Science Foundation funded project (No. 2015M582653), and the Postdoctoral Research Project of Shaanxi Province (No. 2016BSHEDZZ131).

Nomenclature $A$, Area $\left(\mathrm{m}^{2}\right) ; b$, Width of the heater $(\mathrm{mm})$; CHF, Critical heat flux $\left(\mathrm{W} / \mathrm{cm}^{2}\right) ; D_{\mathrm{h}}$, Hydraulic diameter $(\mathrm{mm}) ; g_{0}, 1 g$, Earth gravity level $\left(\mathrm{m} / \mathrm{s}^{2}\right) ; G$, Mass velocity $\left(\mathrm{kg} / \mathrm{m}^{2} \cdot \mathrm{s}\right) ; I_{\mathrm{H}}$, Heating current (A); $k$, Thermal conductivity, $(\mathrm{W} / \mathrm{m} \cdot \mathrm{K}) ; L$, Length of the heater $(\mathrm{mm}) ; q$, Heat flux $\left(\mathrm{W} / \mathrm{cm}^{2}\right) ; Q_{\mathrm{v}}$, The volume flow rate $\left(\mathrm{m}^{3} / \mathrm{s}\right)$; $R_{1}, R_{2}$, Standard resistance (k $\left.\Omega\right) ; t$, Time (s); $T_{\mathrm{w}}, T_{1}, T_{2}, T_{3}, T_{4}$, Wall temperatures $\left({ }^{\circ} \mathrm{C}\right) ; T_{\mathrm{w} \text {-ave }}, T_{1 \text {-ave }}, T_{2 \text {-ave }}, T_{3 \text {-ave }}, T_{4 \text {-ave }}$, Average wall temperature $\left({ }^{\circ} \mathrm{C}\right) ; T_{\mathrm{b}}$, Bulk temperature $\left({ }^{\circ} \mathrm{C}\right) ; T_{\text {sat }}$, Saturation temperature $\left({ }^{\circ} \mathrm{C}\right) ; U_{\mathrm{H}}$, Heating voltage $(\mathrm{V}) ; V$, Inlet liquid velocity $(\mathrm{m} / \mathrm{s}) ; \Delta P$, Pressure drop $(\mathrm{kPa}) ; \Delta T_{\mathrm{sat}}$, Wall superheat $=T_{\mathrm{w}}-T_{\mathrm{sat}}$ $(\mathrm{K}) ; \Delta T_{\text {sub }}$, Fluid subcooling $=T_{\text {sat }}-T_{\mathrm{b}}(\mathrm{K})$.

Greek symbol $\alpha_{x-y}$, Void fraction in $x-y$ plane captured by camera from the top view of channel; $\alpha_{y-z}$, Void fraction in $y-z$ plane at the end of the flow channel; $\mu g$, Gravitational acceleration in microgravity $\left(\mathrm{m} / \mathrm{s}^{2}\right)$. 


\section{References}

Baldassari, C., Marengo, M.: Flow boiling in microchannels and microgravity. Prog. Energy Combust. Sci. 39(1), 1-36 (2013)

Baltis, C., Celata, G.P., Cumo, M., Saraceno, L., Zummo, G.: Gravity influence on heat transfer rate in flow boiling. Microgravity Sci. Technol. 24(3), 203-213 (2012)

Brutin, D., Ajaev, V., Tadrist, L.: Pressure drop and void fraction during flow boiling in rectangular minichannels in weightlessness. Appl. Thermal Eng. 51(1), 1317-1327 (2013)

Celata, G.P.: Flow boiling heat transfer in microgravity: recent results. Microgravity Sci. Technol. 19(3-4), 13-17 (2007)

Celata, G.P., Cumo, M., Gervasi, M., Zummo, G.: Flow pattern analysis of flow boiling in microgravity. Multiph. Sci. Technol. 19(2), 183-210 (2007)

Celata, G.P., Cumo, M., Gervasi, M., Zummo, G.: Quenching experiments inside $6.0 \mathrm{~mm}$ tube at reduced gravity. Int. J. Heat Mass Transf. 52(11), 2807-2814 (2009)

Colin, C., Kannengieser, O., Bergez, W., Lebon, M., Sebilleau, J., Sagan, M., Tanguy, S.: Nucleate pool boiling in microgravity: recent progress and future prospects. Comptes Rendus Mécanique 345(1), 21-34 (2017)

Dhir, V.K., Warrior, G.R., Aktinol, E., Chao, D., Eggers, J., Sheredy, W., Booth, W.: Nucleate pool boiling experiments (NPBX) on the international space station. Microgravity Sci. Technol. 24(5), 307-325 (2012)

Di Marco, P.: Review of reduced gravity boiling heat transfer: European research. Thermal Eng. Micrograv. 20(4), 252-263 (2003)

Di Marco, P., Warrior, G.R., Memoli, G., Takamasa, T., Tomiyama, A., Hosokawa, S.: Influence of electric field on single gas-bubble growth and detachment in microgravity. Int. J. Multiphase Flow 29, 559-578 (2003)

Herman Merte, J.R.: Momentum effects in steady nucleate pool boiling during microgravity. Annals New York Acad. Sci. 1027(1), 196216 (2004)

Honda, H., Wei, J.J.: Effects of fin geometry on boiling heat transfer from silicon chips with micro-pin-fins immersed in FC-72. Int. J. Heat Mass Transf. 46(21), 4059-4070 (2003)

Kawanami, O., Azuma, H., Ohta, H.: Effect of gravity on cryogenic boiling heat transfer during tube quenching. Int. J. Heat Mass Transf. 50(17-18), 3490-3497 (2007)

Kim, J.: Review of reduced gravity boiling heat transfer: US research. Thermal Eng. Micrograv. 20(4), 264-271 (2003)

Kim, J., Benton, J.F., Wisniewski, D.: Pool boiling heat transfer on small heaters: effect of gravity and subcooling. Int. J. Heat Mass Transf. 45(19), 3919-3932 (2002)

Konishi, C., Mudawar, I.: Review of flow boiling and critical heat flux in microgravity. Int. J. Heat Mass Transf. 80, 469-493 (2015)

Konishi, C., Lee, H., Mudawar, I., Hasan, M.M., Nahra, H.K., Hall, N.R., Wagner, J.D., May, R.L., Mackey, J.R.: Flow boiling in microgravity: Part 1-Interfacial behavior and experimental heat transfer results. Int. J. Heat Mass Transf. 81, 705-720 (2015a)

Konishi, C., Lee, H., Mudawar, I., Hasan, M.M., Nahra, H.K., Hall, N.R., Wagner, J.D., May, R.L., Mackey, J.R.: Flow boiling in microgravity: Part 2-Critical heat flux interfacial behavior. Exp. Data Model Config. 15, 16 (2015b)

Kureta, M., Akimoto, H.: Critical heat flux correlation for subcooled boiling flow in narrow channels. Int. J. Heat Mass Transf. 45(20), 4107-4115 (2002)

Luciani, S., Brutin, D., Le Niliot, C., Rahli, O., Tadrist, L.: Flow boiling in minichannels under normal, hyper-, and microgravity: local heat transfer analysis using inverse methods. J. Heat Transf. 130(10), 101502 (2008)

Ma, Y., Chung, J.N.: An experimental study of forced convection boiling in microgravity. Int. J. Heat Mass Transf. 41(15), 23712382 (1998)

Ma, Y., Chung, J.N.: A study of bubble dynamics in reduced gravity forced-convection boiling. Int. J. Heat Mass Transf. 44(2), 399415 (2001a)

Ma, Y., Chung, J.N.: An experimental study of critical heat flux (CHF) in microgravity forced-convection boiling. Int. J. Multiphase Flow 27(10), 1753-1767 (2001b)

Narcy, M., de Malmazet, E., Colin, C.: Flow boiling in tube under normal gravity and microgravity conditions. Int. J. Multiphase Flow 60, 50-63 (2014)

O'Connor, J.P., You, S.M.: A painting technique to enhance pool boiling heat transfer in FC-72. ASME J. Heat Transf. 117, 387393 (1995)

Ohta, H.: Experiments on microgravity boiling heat transfer by using transparent heaters. Nucl. Eng. Des. 175(1), 167-180 (1997)

Ohta, H.: Review of reduced gravity boiling heat transfer: Japanese research. J. Jpn. Soc. Micrograv. Appl. 20(4), 272-285 (2003)

Oka, T., Abe, Y., Mori, Y.H., Nagashima, A.: Pool boiling of npentane, CFC113, and water under reduced gravity: parabolic flight experiments with a transparent heater. J. Heat Transf. 117(2), 408-417 (1995)

Rainey, K.N., You, S.M., Lee, S.: Effect of pressure, subcooling, and dissolved gas on pool boiling heat transfer from microporous, square pin-finned surfaces in FC-72. Int. J. Heat Mass Transf. 46(1), 23-35 (2003)

Raj, R., Kim, J., Mcquillen, J.: Pool boiling heat transfer on the international space station: experimental results and model verification. J. Heat Transf.-Trans. ASME 134, 101504-101501101514 (2012)

Saito, M., Yamaoka, N., Miyazaki, K., Kinoshita, M., Abe, Y.: Boiling two-phase flow under microgravity. Nucl. Eng. Des. 146(1), 451461 (1994)

Serret, D., Brutin, D., Rahli, O., Tadrist, L.: Convective boiling between 2D plates: microgravity influence on bubble growth and detachment. Microgravity Sci. Technol. 22(3), 377-385 (2010)

Sitter, J.S., Snyder, T.J., Chung, J.N., Marston, P.L.: Terrestrial and microgravity pool boiling heat transfer from a wire in an acoustic field. Int. J. Heat Mass Transf. 41(14), 2143-2155 (1998)

Xue, Y.F., Zhao, J.F., Wei, J.J., Li, J., Guo, D.: Wan, experimental study of nucleate pool boiling of FC-72 on smooth surface under microgravity. Microgravity Sci. Technol. 23(Suppl 1), S75-S85 (2011)

Xue, Y.F., Zhao, J.F., Wei, J.J., Zhang, Y.H., Qi, B.J.: Experimental study of nucleate pool boiling of FC-72 on micro-pin-finned surface under microgravity. Int. J. Heat Mass Transf. 63, 425-433 (2013)

Zell, M., Straub, J., Weinzierl, A.: Nucleate pool boiling in subcooled liquid under microgravity results of texus experimental investigations. In: 5th European Symposium on Material Science under Microgravity, pp. 327-333 (1984)

Zhang, H., Mudawar, I., Hasan, M.M.: Flow boiling CHF in microgravity. Int. J. Heat Mass Transf. 48(15), 3107-3118 (2005)

Zhang, Y.H., Wei, J.J., Xue, Y.F., Kong, X., Zhao, J.F.: Bubble dynamics in nucleate pool boiling on micro-pin-finned surfaces in microgravity. Appl. Thermal Eng. 70(1), 172-182 (2014)

Zhao, J.F.: Two-phase flow and pool boiling heat transfer in microgravity. Int. J. Multiphase Flow 36(2), 135-143 (2010) 